\title{
WHY HOSPITAL WASTE MANAGEMENT IS IMPORTANT TO THE ENVIRONMENT?: A SYSTEMATIC LITERATURE REVIEW
}

\author{
Suriati Deraman ${ }^{1, *}$, Khai Loon Lee ${ }^{2}$, and Puteri Fadzline Muhamad Tamyez² \\ ${ }^{1}$ Faculty of Busines, DRB Hicom University of Automotive Malaysia, 26600 Pahang, Malaysia. \\ ${ }^{2}$ Faculty of Industrial Management, Universiti Malaysia Pahang, 26600 Pahang, Malaysia.
}

\begin{abstract}
Today, the healthcare industry has grown in importance as the number of hospitals has increased in response to the increased number of patients. This signifies that the world will be facing a more critical environment as a result of waste generation by hospitals. However, there are still insufficient studies that systematically review the existing literature on hospital waste management. Thus, this systematic literature review focuses on hospital waste management and its environmental impact. The results from Google Scholar and Science Direct show 80 articles starting from 2015 to 2020 . Only 12 articles fulfil the criteria for further analysis. Most studies indicated the presence of hospital waste procedures such as waste segregation, a lack of awareness among clinical staff, poor facilities and government enforcement. The study contributes to the body of knowledge and the industry. This study explains the importance and environmental impact of hospital waste management. A recommendation for future research is provided.
\end{abstract}

\author{
ARTICLE HISTORY \\ Received: 26-1-2021 \\ Revised: 5-5-2021 \\ Accepted: $16-8-2021$ \\ KEYWORDS \\ Hospital waste \\ Healthcare waste \\ Clinical waste \\ Biomedical waste \\ Environment impact
}

\section{INTRODUCTION}

Hospital waste contains different forms of waste from hospitals, nursing homes, medical research facilities, clinics, and medical shops that vary in character and composition (Manzoor \& Sharma, 2019). The majority of hospitals generate waste comparable to domestic waste, and it is becoming increasingly imperative that hospitals find ways and improve strategies to manage the waste sustainably, according to Baaki, Baharun, Ali, and Jaafar (2018). A study conducted by Mekonnen, Geremaw, and Asefa (2020) shows that more than half (57.4 per cent) of the total healthcare waste produced in the hospital was general or non-risk, with the remaining 42.25 per cent being hazardous healthcare waste. Recycling is also an alternative to reducing hospital waste, as it conserves natural resources, saves electricity, lowers disposal costs, reduces toxic air and water pollution, saves money, and creates jobs (Asuamah, Kumi, \& Kwarteng, 2012).

Today, several hospitals are beginning to examine recycling or donating leftovers that are still accessible in developing countries such as Indonesia, Mexico, and Singapore (Halder \& Singh, 2018) mentioned that increasing recycling of urban waste has become a priority for sustainable environmental management and planning in both developed and developing countries. Furthermore, waste management practices can improve organisational performance systematically and effectively, particularly in the healthcare sector (Roslan, Habidin, Zainudin, Norazlan, \& Abdul Hadji, 2014). On the other hand, ineffective waste management policies would cause exposure to health risks and real environmental problems (Manzoor \& Sharma, 2019). Therefore, the review of literature plays a critical role as a base for all study forms.

This approach is the basis for creating expertise, creating strategy and implementation guidance, the proof of an impact, and, if done well, having the potential to generate new ideas and directions for a specific area (Snyder, 2019). This paper attempts to contribute to the existing body of knowledge by developing a systematic review on hospital waste management using a systematic method. According to Weng, Chen, and Chen (2015), systematic literature review (SLR) is recognised, referenced; and methods for data analysis, including analysis methods, research rigour, and strength of evidence.

\section{HOSPITAL WASTE MANAGEMENT}

This study is conducted to analyse hospital waste management and discuss the environmental and health impacts. Numerous researches have been conducted on hospital waste management and its impact from multiple perspectives such as management, practices, assessment and risk (Ayse, Dursun, Hysen, 2014; Eigitait, 2013; Mochungong, 2011; Sengodan, 2014; Al Razib, 2017). Despite the fact that many studies on hospital waste have been conducted, the amount is still insufficient. Figure 1 depicts the process of managing waste generated by hospital activities to provide a clear understanding of the hospital waste process. 


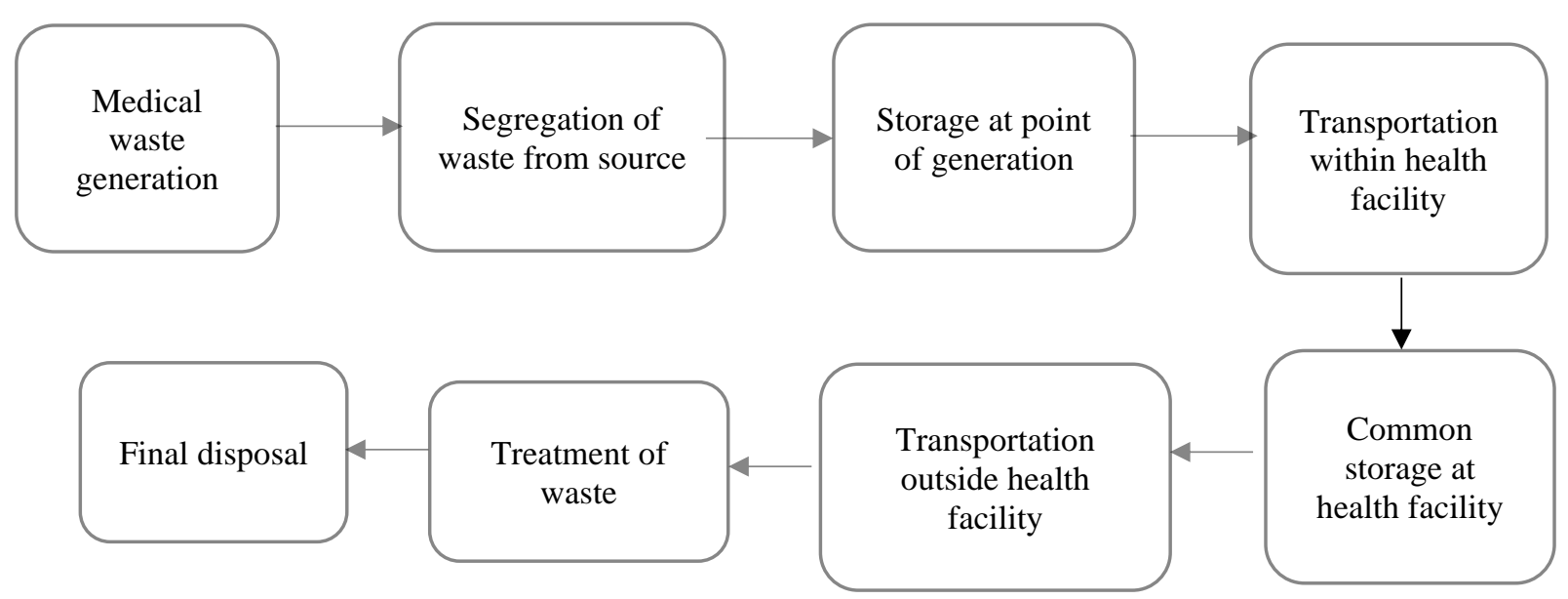

Figure 1. Hospital Medical Waste Chain (Source: Adoption from Olaniyi, Ogola, and Shitangano (2018))

This review is guided by the central research question, which is why hospital waste management is important for the environment. This study aims to fill the gap by reviewing previous literature systematically in order to gain a better understanding of hospital waste management around the world.

\section{METHODOLOGY}

\section{The Review Protocol - ROSES}

The ROSES review protocol was used in this study to provide standard reporting for Systematic Evidence Synthesis and design for systematic review and maps for the environment field (Haddaway, Macura, Whaley, \& Pullin, 2018). ROSES aims to increase and maintain high standards in conducting systematic reviews and mapping by increasing transparency and facilitating quality assurance. The authors believed that ROSES better reflects the nuances and heterogeneity of situations in which they work as reviewers than PRISMA.

The review protocol explains the systematic searching strategy, which consists of three main sub-processes. The subprocesses include identification, screening (inclusion and exclusion criteria), and eligibility. The next process is an appraisal of the quality of the selected articles, which involves the explanation of the strategy applied to ensure the quality of the articles to be reviewed. The final process explains the data abstracted for the review and how-the data was analysed and validated.

\section{Formulation of Research Questions}

The authors are interested in using PICo to assist in developing relevant research questions for the review. PICo is based on three main concepts, which are Population or Problem, Interest, and Context. Based on the concepts, the authors included hospital workers (population), adoption of a new process (Interest), and Malaysia (Context), which guided the authors to formulate its main research question, which is what is the impact of hospital waste management on the environment.

\section{Systematic Searching Strategies}

There are two databases used in the systematic searching strategies processes: identification, screening, and eligibility. The first database used is Web of Science by using keywords TS = ("hospital* waste*" OR "healthcare* waste*" OR "clinical waste*" OR "medical waste*" OR "biomedical waste*", "pathological waste*", "impact*", "organisation", "performance*"). The second database used is Google Scholar.

The appropriate combination of keywords such as "hospital waste", "healthcare waste", "clinical waste", "medical waste", "biomedical waste", "pathological waste", "impact", "organisation”, "performance" and aborigines was practised using functions of page searching and the Boolean operator (OR, AND).

\section{Identification}

Identification is the process of searching any synonym, related terms, and variations for the study's main keywords, which are hospital waste management impact on organisational performance review. The above-mentioned keyword development was then carried out (Piper, 2013). The total number from both sources resulted in a total of 80 articles. 


\section{Screening}

Researchers must screen 80 selected articles by choosing the criteria for article selection based on the database's sorting function. The selection is based on the research question, as suggested by (Piper, 2013). In this study, articles were selected from 2015 until 2020. All articles were reviewed by reading the references to meet the objective of the study. To avoid confusion in understanding, only articles with empirical data and published in English were selected to ensure the quality of the review. This process had excluded eight articles as they did not meet the inclusion criteria. The remaining 72 articles were used for the third process, which is eligibility.

\section{Eligibility}

The third process involved the authors manually monitoring the retrieved articles to ensure that all of the remaining articles (after the screening process) met the criteria. This was done by reading the titles and abstracts of the articles. This process excluded 60 articles because the focus was on vulnerability rather than the scope of practices, assessment, types of waste, and environmental impact. Overall, 12 articles were selected.

\section{Quality Appraisal}

In ensuring the quality of the article's content, the remaining articles were presented to two experts for quality assessment. The literature review suggested that experts should classify the remaining articles into three categories: high, moderate, and low. Only articles with a high or moderate rating should be reviewed. The expert focuses on the articles' methodology to determine the rank of the quality to be included in the review. Both authors must mutually agree that the quality must be at least moderate.

\section{Data Abstraction And Analysis}

This study relied on an integrative review. This technique enables the review to include a variety of research designs (quantitative, qualitative, and mixed-method). According to Noyes et al. (2019), the best way to synthesise or analyse integrative data is to employ a qualitative or mixed-method technique. Table 1. shown the researchers read the 12 articles, paying special attention to the abstract and discussion sections. The data abstraction was conducted based on the research question, which means that any data from the review studies that can answer the research questions were used.

The first step in thematic development is to generate themes. During this process, the authors tried to identify patterns that emerged from all reviewed articles' abstract data. The authors then re-examined the seven sub-groups. The next process was to review the accuracy of this theme. Throughout this process, the authors re-examined all the main and subthemes generated to ensure their usefulness and accurate representation of the data. Four sub-themes were eliminated during the process.

\section{Hospital Waste Management Towards the Environment}

Table 1. List of Articles Reviewed

\begin{tabular}{|c|c|c|c|c|c|c|}
\hline No & Studies & Country & Practices & Assessment & $\begin{array}{l}\text { Hospital } \\
\text { waste } \\
\text { generation }\end{array}$ & Environment \\
\hline 1 & $\begin{array}{l}\text { Adu, Gyasi, Essumang, and } \\
\text { Otabil (2020) }\end{array}$ & India & $\sqrt{ }$ & & & $\sqrt{ }$ \\
\hline 2 & Susi, Enri and Chaerul (2020) & Indonesia & & & $\sqrt{ }$ & \\
\hline 3 & Tfaily and Moussa (2020) & $\begin{array}{l}\text { South } \\
\text { Lebanon }\end{array}$ & $\sqrt{ }$ & $\sqrt{ }$ & & \\
\hline 4 & $\begin{array}{l}\text { Musa, Mohamed, and Selim } \\
(2020)\end{array}$ & Qatar & & $\sqrt{ }$ & & \\
\hline 5 & Ugwu et al., (2019) & Nigeria & & & $\sqrt{ }$ & \\
\hline 6 & $\begin{array}{l}\text { Rajan, Robin, and Vandanarani } \\
\text { (2018) }\end{array}$ & India & $\sqrt{ }$ & & & \\
\hline 7 & $\begin{array}{l}\text { Niyongabo, Jang, Kang and } \\
\text { Sung (2019) }\end{array}$ & Ethiopia & & $\sqrt{ }$ & $\sqrt{ }$ & \\
\hline 8 & Zamparas et al., (2019) & Greece & & $\sqrt{ }$ & & \\
\hline 9 & Gunawardana (2018) & Colombo & $\sqrt{ }$ & & & $\sqrt{ }$ \\
\hline 10 & $\begin{array}{l}\text { Ali, Ijaz, Aman, Nasir and } \\
\text { Anjum (2017) }\end{array}$ & Pakistan & & & $\sqrt{ }$ & \\
\hline 11 & $\begin{array}{l}\text { Baaki, Baharum and Akashah } \\
\text { (2017) }\end{array}$ & Nigeria & $\sqrt{ }$ & & & \\
\hline 12 & Kalaivani (2017) & India & $\sqrt{ }$ & & $\sqrt{ }$ & $\sqrt{ }$ \\
\hline
\end{tabular}




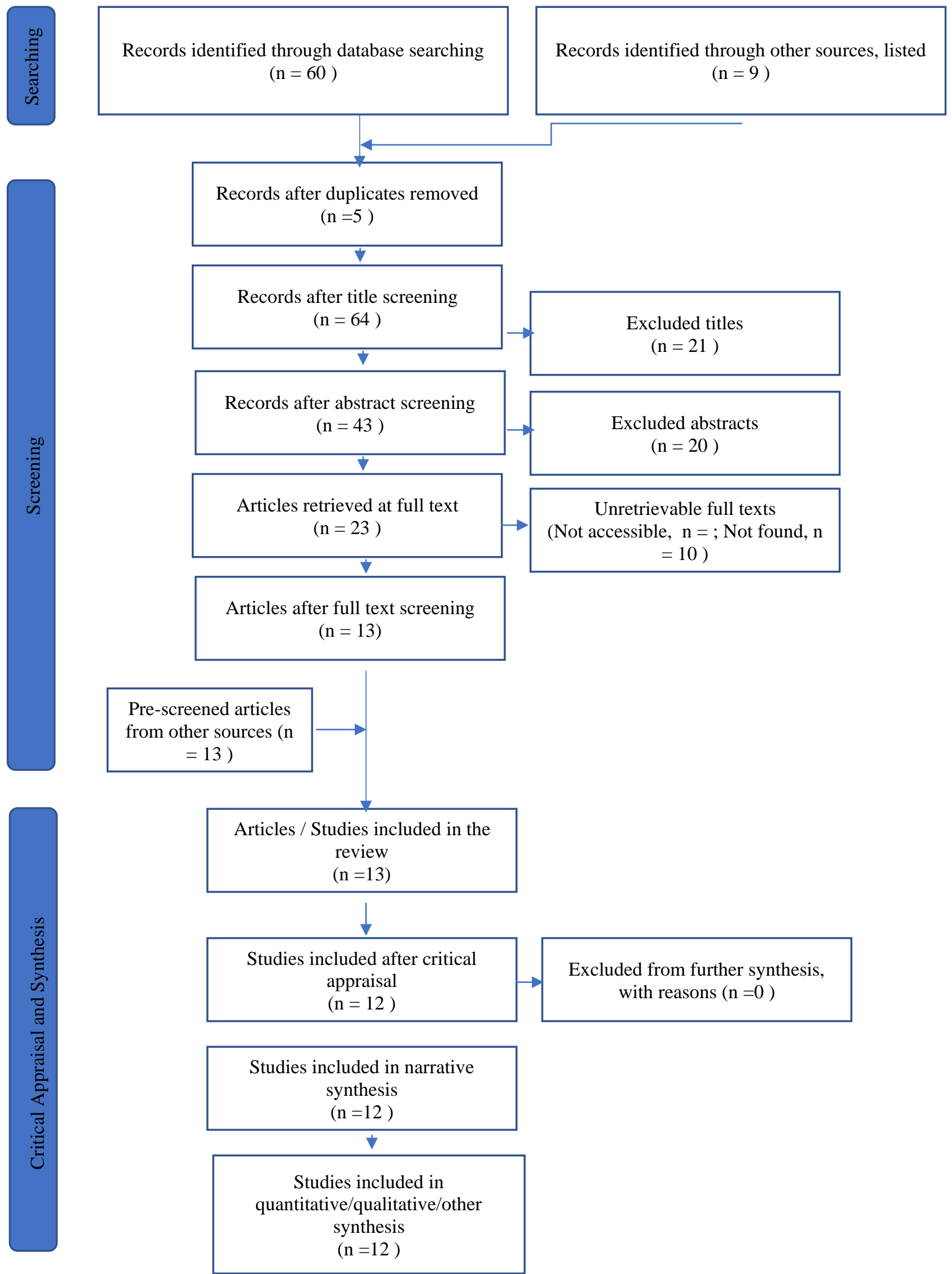

Figure 2. Flow Diagram for Systematic Reviews. Version 1.0 (Adaption from: Haddaway et al., (2018)) 


\section{RESULTS}

\section{Background of the Selected Articles}

The review managed to obtain 12 selected articles. Based on the thematic analysis, four themes were developed, namely practices, hospital waste generation, assessment, and environment, to answer the research questions.

\section{First Theme: Hospital Waste Practices}

Hospitals provide many services, such as short-term hospitalisation, emergency room services, general and speciality surgical services, $\mathrm{x}$-ray/radiology services, etc. These activities contribute to waste generation and directly have an impact on the environment if poor practices are followed. Proper hospital waste management is the foundation of hospital cleanliness, hospital hygiene, and maintenance activities (Adu et al., 2020). Many countries are now developing guidelines or policies to manage hospital waste. The study found that training, sensitisation, and awareness are considered the most critical factors, followed by environmental legislation in compliance with international environmental rules/regulations; and specific and elaborate regulations concerning medical waste (Baaki et al., 2017). Unfortunately, a study conducted by Rajan et al. (2018) shows that the current classification system of SMW in national guidelines was not appropriate for safe collection and disposal (disposal techniques adopted for Ayurveda biomedical wastes are esewage/drains, incineration, and landfill).

They also found that while contaminated sharps were separated into brown safety boxes, the colour coding for other infectious waste containers was inconsistent across health care facilities. The same problems arise from the workers' unsatisfactory practices regarding policies, regulations, procedures, safety issues, and awareness (Tfaily \& Moussa, 2020). With that, governments should provide legislation and regulatory support. Organisations of all sizes must have a positive attitude, awareness, capability, and technology to initiate improvements for waste management processes and be prepared to adapt to new trends (Gunawardana, 2018).

This study stresses the need for increased participation at both the internal (HCF) and external (ministry) levels in creating awareness about the risk potential of medical wastes and existing guidelines to encourage acceptable practices and enactment of specific legislation dealing with MWM (Baaki et al., 2017). To improve current practices, nurses must be well-equipped with skills and practices in managing medical waste. The percentage of nurses who correctly colourcoded different waste categories were $92.8 \%$. After analysing and summarising hospital waste practices, many hospitals have their own method to manage their waste, including policies, procedures, and disposal methods. Other than that, the involvement from the government also plays a primary role in supporting this method.

\section{Second Theme: Assessment}

The assessment is critical for measuring the effectiveness of hospital waste management. Waste management is becoming a significant issue since they pose many health risks and cause environmental damage (Tfaily \& Moussa, 2020). Based on the assessment conducted by researchers, evaluated hospitals showed good management of healthcare wastes (Tfaily \& Moussa, 2020). However, another study shows unsatisfactory practices in these hospitals in terms of policies, regulations, procedures, safety issues, and awareness (Tfaily \& Moussa, 2020). Zamparas et al. (2019) used four elements to assess hospital waste practices a) current legislation and directives issued for medical waste management in Greece and among other EU-members; b) contribution of healthcare wastes (HCW) generation rate on social and economic parameters in selected European countries; c) available procedures, techniques, and methods for disposing of infectious wastes in the healthcare studied, and; d) propositions for integrated management of such hazardous wastes. Other studies were interested in examining the current collection, storage, treatment, and disposal methods used in healthcare facilities and proposing improvements to practices that needed to be improved immediately (Adu et al., 2020).

\section{Theme 3: Hospital waste generation}

The hospital waste generation rate is 163.9 tons/month. Community health centres and clinics contribute 1.1 and 3.5 tons of waste per month, respectively (Susi et al., 2020). The total hospital waste generated is composed of 55\% noninfectious waste, $15 \%$ infectious waste, $25 \%$ bio-hazardous waste, $2 \%$ sharps waste, and $3 \%$ chemical waste is the generation in these hospitals (Ali et al., 2017). Some methods of diagnosis and treatment produce more waste than others (Kalaivani, 2017). Several types of waste were found, which could be classified as sharps, including syringes and needles, ampoules and vials, saline bags, and infusion sets.

The waste generation rate varies from ward to ward. The difference is because of the characteristics of each ward. Table 2 shows the total waste generated from three categories per kg/ward/day. Category A recorded the highest amount due to the multiple services offered compared to other categories and the number of beds (Ugwu et al., 2019). Each ward requires a different type of diagnosis and treatment. Other studies calculated total waste generation by using per bed and the number of medical wastes per health care worker and found that they were 3.6 and 5.9 times higher in public HCFs than in private HCFs, respectively (Niyongabo et al., 2019). 
Table 2. Total waste generated (adopted from Ugwu et al. (2019))

\begin{tabular}{lc}
\hline \multicolumn{1}{c}{ Category } & $\mathrm{Kg} /$ ward/day \\
\hline Category A - Hospital & 59.811 \\
Category B - Private Hospital & 32.53 \\
Category C - Primary health centre & 31.53 \\
\hline
\end{tabular}

\section{Theme 4: Environmental}

Hospital waste management faces the risk of cross-contamination from hospital activities. The lack of thorough waste sorting at the point of generation, the disposal of hazardous and non-hazardous waste types, and the use of open-fire pits and substandard incinerators for burning infectious waste (Adu et al., 2020). Hospital waste can be reduced with the cooperation of all workers and patients. However, nursing personnel play a significant role in the whole process (Musa et al., 2020). Hospital waste may pollute the air and water. Pollution refers to substances in the natural environment that are the result of human activity that might harm humans, animals, or the environment (Kalaivani, 2017).

The implementation of sustainable waste management can gain benefits through this project. The implementation depends on private institutes in the healthcare sector using world-accepted waste disposal methods (Gunawardana, 2018). Sustainable waste management aims to address waste's health and environmental impacts through recovery, recycling, reuse of resources, and minimisation of waste streams.

According to Figure 2, other strategic waste management is divided into two categories: non-waste and waste. Nonwaste includes waste prevention and preparation for reuse, as well as waste that will be recycled, recovered, or disposed of in the final destination. (Ferrari, Gamberini, \& Rimini, 2016). Another study also agreed that implementing a sustainable waste management hierarchy in hospital waste could protect the intention of directing more efforts toward waste prevention, with waste disposal considered the last resort for waste that must inevitably end up at waste disposal mechanisms (Baaki et al., 2018).

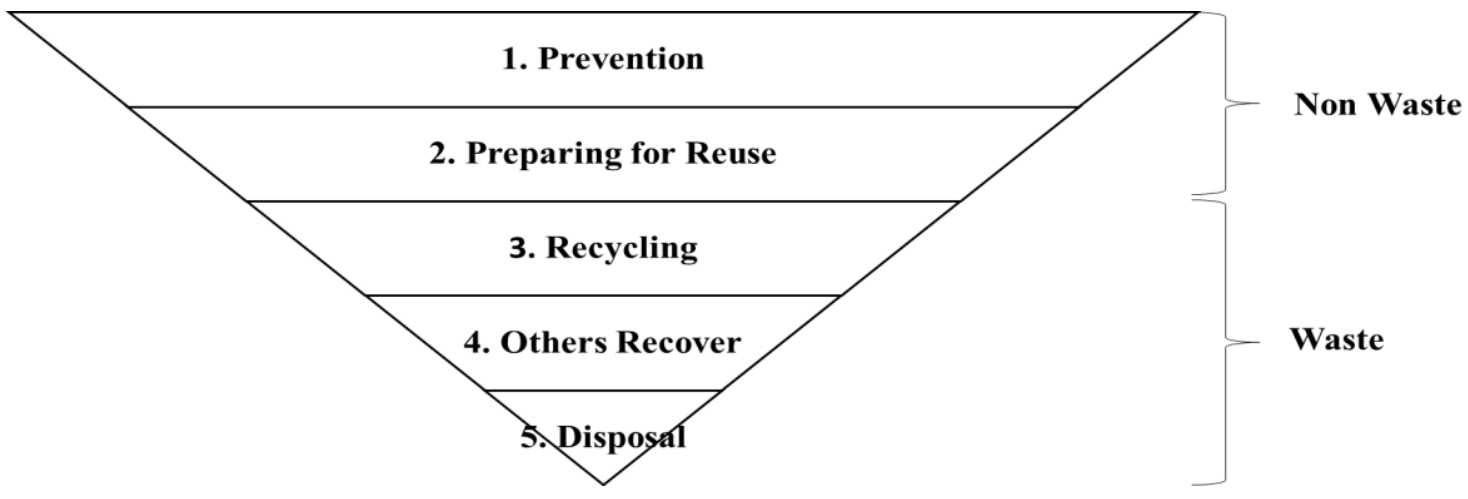

Figure 2. The strategic waste hierarchy (adopted from: Ferrari et al., (2016))

\section{DISCUSSION}

Currently, hospital waste management becomes a critical issue around the world. Mismanagement of hospital waste affects all individuals, particularly healthcare providers. Generally, hospital waste management encompasses the processes of segregation, collection, storage, transportation, treatment to disposal (Mmereki, Baldwin, Li, \& Liu, 2017). However, in this systematic literature review, studies mentioned the absence of waste practices (Baaki et al., 2018; Gunawardana, 2018; Kalaivani, 2017; Rajan et al., 2018; Tfaily \& Moussa, 2020) This is most likely due to a lack of appropriate utilities, awareness, and a lack of enforcement of laws and regulations. The findings show that the government, hospital management, and staff all play a role in implementing the right practices required by law and procedure. To ensure the effectiveness of the practices in the future, an assessment of the improvement process is required. The impact of good practices and assessments will be seen in the amount of waste generated. High waste generation indicates poor waste handling and management responsibility in reducing waste at their organisation. In the end, this will have an impact on the environment through disposal processes such as incineration and landfill. 


\section{RECOMMENDATION}

This systematic literature review recommends conducting a study about behavioural impact on organisational performance. This is because, due to a lack of focus on hospital waste, several studies primarily focus on environmental impact. Many researchers focus on core business activities such as treating patients, improving processes and procedures. Besides, recycling practices in the healthcare industry should be considered as a means of reducing waste disposal and preventing environmental pollution.

\section{CONCLUSION}

In conclusion, many researchers are now interested in conducting a study on hospital waste. Most research focuses on waste generation, disposal, alternative treatment, environmental and health impact, and other topics. They also tried to find out the lack of accessible guidelines, utilities, inadequate training, and other issues to improve current hospital waste management. The study stresses this to prevent our environment from polluting for future generations. It is hoped that this study will prevent waste mismanagement in hospitals for many years to come.

The study and its findings have theoretical and practical implications. The healthcare industry must consider alternative approaches to managing and improving current hospital waste. The results can also be used to develop new waste management implementation and operational strategies in the healthcare industry. The findings allow for muchneeded in-depth studies of hospital waste practices from different stakeholders and research design perspectives.

\section{DECLARATION OF COMPETING INTEREST}

The authors declare that they have no known competing financial interest or personal relationship that could have influenced the work reported in this paper.

\section{REFERENCES}

Adu, R. O., Gyasi, S. F., Essumang, D. K., \& Otabil, K. B. (2020). Medical Waste-Sorting and Management Practices in Five Hospitals in Ghana Medical Waste-Sorting and Management Practices in Five Hospitals in Ghana, (March). https://doi.org/10.1155/2020/2934296

Ali, S. S., Ijaz, N., Aman, N., Nasir, D. A., \& Anjum, D. L. (2017). Clinical waste management practices in district faisalabad. Earth Sciences Pakistan. https://doi.org/10.26480/esp.02.2017.04.06

Asuamah, S. Y., Kumi, E., \& Kwarteng, E. (2012). Attitude Toward Recycling and Waste Management: a Survey of Marketing Students in Sunyani Polytechnic, Ghana. Advances in Arts, Social Sciences and Education Research, 2(5), 158-167. Retrieved from http://www.ejournal.sedinst.com

Ayse, Sukru Dursun, Mankoll Hysen, C. (2014). Hospital Solid Wastes and Its Effect on Environment. J. Int. Environmental Application \& Science, 8(December 2013), 733-737.

Baaki, T. K., Baharum, M. R., \& Akashah, F. W. (2017). Critical success factors of medical waste management implementation in healthcare facilities in Nigeria: A case study. Journal of Design and Built Environment. https://doi.org/10.22452/jdbe.vol17no1.2

Baaki, T. K., Baharun, M. R., Ali, A. S., \& Jaafar, M. hasni. (2018). Exploring sustainable healthcare waste management implementation in teaching hospitals in Malaysia. LKMU Research Online.

Eigitait, Y. (2013). Staff Perceptions and Practice for Hospital Waste Management With Reference to Recycling in the UK versus Libya, a Comparative Study John Moores University for the degree of Doctor of Philosophy, (June).

Ferrari, K., Gamberini, R., \& Rimini, B. (2016). The waste hierarchy: A strategic, tactical and operational approach for developing countries. the case study of Mozambique. International Journal of Sustainable Development and Planning, 11(5), 759-770. https://doi.org/10.2495/SDP-V11-N5-759-770

Gunawardana, K. D. (2018). An analysis of medical waste management practices in the health care sector in Colombo. Management of Environmental Quality: An International Journal. https://doi.org/10.1108/MEQ-02-2018-0032

Haddaway, N. R., Macura, B., Whaley, P., \& Pullin, A. S. (2018). ROSES Reporting standards for Systematic Evidence Syntheses: Pro forma, flow-diagram and descriptive summary of the plan and conduct of environmental systematic reviews and systematic maps. Environmental Evidence. https://doi.org/10.1186/s13750-018-0121-7

Halder, P., \& Singh, H. (2018). Predictors of recycling intentions among the youth: A developing country perspective. Recycling, 3(3), 1-16. https://doi.org/10.3390/recycling3030038

Kalaivani, V. (2017). Biomedical Waste Disposal System In A Hospital. IOSR Journal of Dental and Medical Sciences, 16(6), 24-29. https://doi.org/10.9790/0853-1606022429

Manzoor, J., \& Sharma, M. (2019). Impact of Biomedical Waste on Environment and Human Health. Environmental Claims Journal, 31(4), 311-334. https://doi.org/10.1080/10406026.2019.1619265

Mekonnen, B., Geremaw, M., \& Asefa, A. (2020). Assessment of healthcare waste generation rate and management practice in Assessment of healthcare waste generation rate and management practice in the case of Mizan-Tepi Tepi University Teaching Hospital Southwest, Ethiopia. Intern Res J of Med Scie, 8(1), 1-8.

Mmereki, D., Baldwin, A., Li, B., \& Liu, M. (2017). Healthcare waste management in Botswana: storage, collection, treatment and disposal system. Journal of Material Cycles and Waste Management. https://doi.org/10.1007/s10163015-0429-0 
Mochungong, P. I. K. (2011). Environmental Exposure and Public Health Impacts of Poor Clinical Waste Treatment.

Musa, F., Mohamed, A., \& Selim, N. (2020). Assessment of Nurses' Practice and Potential Barriers Regarding the Medical Waste Management at Hamad Medical Corporation in Qatar: A Cross-Sectional Study. Cureus, 12(5). https://doi.org/10.7759/cureus.8281

Niyongabo, E., Jang, Y. C., Kang, D., \& Sung, K. (2019). Generation, management practices and rapid risk assessment of solid medical wastes: a case study in Burundi. Journal of Material Cycles and Waste Management. https://doi.org/10.1007/s10163-019-00854-0

Noyes, J., Booth, A., Moore, G., Flemming, K., Tunçalp, Ö., \& Shakibazadeh, E. (2019). Synthesising quantitative and qualitative evidence to inform guidelines on complex interventions: clarifying the purposes, designs and outlining some methods. BMJ Global Health, 4(Suppl 1), e000893. https://doi.org/10.1136/bmjgh-2018-000893

Olaniyi, F., Ogola, J., \& Shitangano, T. (2018). A Review of Medical Waste Management in South Africa. Open Environmental Sciences, 10(1), 34-45. https://doi.org/10.2174/1876325101810010034

Piper, R. J. (2013). How to write a systematic literature review: a guide for medical students. National AMR, 1(2), 1-8. Retrieved from http://cures.cardiff.ac.uk/files/2014/10/NSAMR-SystematicReview.pdf\%0Acures.cardiff.ac.uk/files/2014/.../NSAMR-Systematic-Review.pdf

Rajan, R., Robin, D. T., \& Vandanarani, M. (2018). Biomedical waste management in Ayurveda hospitals - current practices \& future prospectives. Journal of Ayurveda and Integrative Medicine. https://doi.org/10.1016/j.jaim.2017.07.011

Roslan, M. H., Habidin, N. F., Zainudin, M. Z., Norazlan, A. N. I., \& Abdul Hadji, N. S. (2014). Waste Management Practices and Organization Performance in Malaysian Healthcare Industries. Journal of Applied Science And Research, 2(JANUARY), 14-22.

Sengodan, V. (2014). Segregation of biomedical waste in an South Indian tertiary care hospital. Journal of Natural Science, Biology and Medicine, 5(2), 378. https://doi.org/10.4103/0976-9668.136194

Shamim Al Razib, M. (2017). Study of Clinical Waste Management at Rajshahi Medical College Hospital (RMCH) in Bangladesh. International Journal of Environmental Protection and Policy, 5(2), 26. https://doi.org/10.11648/j.ijepp.20170502.12

Snyder, H. (2019). Literature review as a research methodology: An overview and guidelines. Journal of Business Research, 104(March), 333-339. https://doi.org/10.1016/j.jbusres.2019.07.039

Susi, W. A., Enri, D., \& Chaerul, M. (2020). Solid Waste Generation from Healthcare Facilities in Surabaya City Indonesia. E3S Web of Conferences, 148(August 2017), $2019-2021$. https://doi.org/10.1051/e3sconf/202014801006

Tfaily, M., \& Moussa, S. (2020). Assessment of Healthcare Waste Management in Hospitals of South Lebanon, 2(2).

Ugwu, E. I., Ekeleme, A. C., Okolie, S. T. A., Ibe, O. P., Chieke, C. F., Ibearugbulem, H. O., ... Ugwu, E. C. (2019). Characterisation of Medical Wastes from selected Hospitals in Umuahia, Nigeria. In Journal of Physics: Conference Series. https://doi.org/10.1088/1742-6596/1378/4/042058

Weng, H. H. R., Chen, J. S., \& Chen, P. C. (2015). Effects of green innovation on environmental and corporate performance: A stakeholder perspective. Sustainability (Switzerland). https://doi.org/10.3390/su7054997

Zamparas, M., Kapsalis, V. C., Kyriakopoulos, G. L., Aravossis, K. G., Kanteraki, A. E., Vantarakis, A., \& Kalavrouziotis, I. K. (2019). Medical waste management and environmental assessment in the Rio University Hospital, Western Greece. Sustainable Chemistry and Pharmacy. https://doi.org/10.1016/j.scp.2019.100163. 


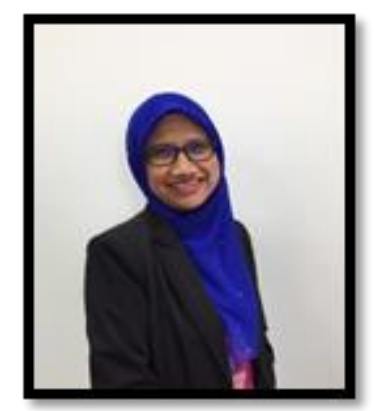

Suriati Deraman is a Supply Chain Management lecturer at DRB- HICOM University of Automotive Malaysia since August 2017. Previously, from 2008 to 2017, she worked in the healthcare industry as a Quality Officer and Procurement Officer. She is a certified professional scheduled waste from the Environment Institute of Malaysia since 2015.

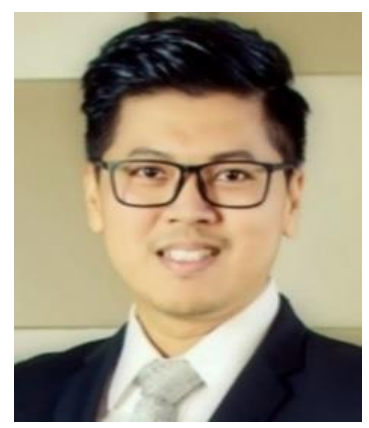

Ts. Dr Lee Khai Loon is a Senior Lecturer and the Head of Program (Business Engineering) in at Faculty of Industrial Management (FIM), Universiti Malaysia Pahang (UMP). He specialised in supply chain management, technology management, operation management, industrial engineering, and business management. He holds a Doctor of Philosophy (PhD) in Supply Chain Management and a Bachelor Degree in Technology Management from the School of Technology Management and Logistics, Universiti Utara Malaysia. He has a long industrial experience in the fastmoving consumer goods (FMCG), fashion, food and beverage, and manufacturing industries. He started his first academic career in 2015 by teaching undergraduate and postgraduate students in the university. He has received numerous academic, research, and product innovation awards. He is a chartered member of The Chartered Institute of Logistics and Transport (CMILT) Malaysia and UK, a Professional Technologist in Malaysia Board of Technologists (MBOT), an HRDPF Certified Trainer (TTT), a MonsoonSIM Certified Trainer for, a Mendeley Advisor, and a Certified Microsoft Innovative Educator.

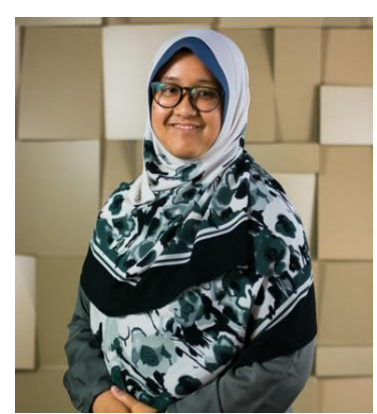

Assoc. Prof. Dr. Puteri Fadzline bt Muhamad Tamyez is currently the Deputy Dean of Research and Postgraduate Studies in Faculty of Industrial Management, Universiti Malaysia Pahang. She graduated from Universiti Technology MARA, Shah Alam, with a PhD in Business Management and from Universiti Sains Malaysia, Penang with BSc and MSc degrees in Bioresources, Paper and Coating Technology under the School of Industrial Technology. Prior to joining Universiti Malaysia Pahang, she had accumulated industrial experiences in the furniture and wood flooring industries for 4 years. At both companies, she is responsible for matters related to Quality Control and Production processes. Her research interests are Business Management, Innovation Management, Product Management, and Research Methodology. She can be reached at the Faculty of Industrial Management, Universiti Malaysia Pahang, Lebuhraya Tun Abdul Razak, 25300, Kuantan, Pahang, via email at fadzline@ump.edu.my or by phone at $+09-549$ 2445. 